\title{
Discussion on Development Ideas of Henan Photography and Photography Service Industry
}

\author{
Liping Li \\ School of Art and Design \\ Huanghe Science and Technology College \\ Zhengzhou, China
}

\begin{abstract}
Today, as virtually everyone considers himself of herself a photographer, the commercial photography industry experiences a "suicide-cutthroat competition". Both large photography agencies and small photography studios have to lower their prices to survive within the industry. Such a cutthroat competition will doom to lead to the decline of image quality in the photography. Under such a vicious competition, due to lacking innovation ability and policy response, many photography agencies have closed down, and the rest still struggle to keep their heads above water. As to the digital art photography, various photographies enter to the picture market, thus leading to the phenomena of immature creative ideas and poor connotation of works from another side. Image product is the nourishment for the mind for the majority of people and is especially favored by most teenagers. We need to strengthen the management for content of image product, especially the examination for imported content. Strictly strike and completely eradicate illegal business, increase the protection for intellectual property of image derivatives, maintain healthy market order, build good development environments, perfect the development mechanism of the whole image industry, and facilitate the benign development of image industry.
\end{abstract}

Keywords-image and image serve industry; cultivating talents; industrial standard

\section{INTRODUCTION}

Image is one of the best ways to communicate globally, eradicating any language barriers. As a medium of cultural symbols and artistic dissemination, image certainly will carry the function of culture and dissemination. In the culture era of "picture-reading", image service has become a culture phenomenon closely related to people's lives, having a far-reaching influence on our own lives. As a worldwide culture and art carrier, no matter the angle of economic value or the angle of cultural value, image has inestimable effects.

In the era of digital, the creative energy hidden in digital photography has swept the world like a flood. No matter whether you accept it or not, it's convenient, efficient and facilitating transmission functions have proven popular amongst all, and it has become the pronoun of "fashion" in the mind of people. The appearance of this phenomenon, in this evolution era, has become the true "folksy" image tool of today's photography. In almost two hundred years of photography development, this development keeps abreast of the times, thoroughly changing the "arrogant attitude" of photography, turning the so-called "noble art" into "civilian art". Image service markets once could not find the direction of development due to such a change. Facing the digital era of "Everybody photographs", the photography market entered into a chaos period. Digital brought convenience to people's lives, meanwhile, its adverse impacts also show that photography amateurs have indulged in showing off their technological means, which is consequently destroying the "internal" culture of photography. The picture shooting becomes simple, but the connotation and significance of image weakens instead of strengthening.

\section{VAluing TALENTS, StRENGTHENING THE}

\section{ATTRACTION, EDUCATION AND RESERVE OF TALENTS}

In the present world, the development of various industries cannot ignore the support of talents, especially their core talents. Similarly, in the Henan image industry, the key bothering its development is the lack of talented people, especially the attraction and education of senior image talents.

The originality and market operation talents are woefully inadequate. In recent years, many colleges and universities in Henan province have successively set up the image major, but image talent training is far from satisfying the development needs of the current image industry in both quality and quantity. Zhengzhou's image industry at present seriously lacks a curators planning and marketing talents with revolutionary characteristics. This is also one of the root reasons why the picture market of Henan Province cannot attract the audience, resulting in the market struggling to blossom. The shortage of operation talents restricts the upgrade in the industry. The lack of talents is a big bottleneck influencing the industrial development of picture market in Henan Province, which is directly related to the prosperity or decline, success or failure of the industry. To adapt to the demand of Chinese economic and social development and adapt to the game rule of market law, on the basis of inheriting and carrying forward the creative experience of photography predecessors, we shall also boldly innovate and reform, show the creative spirit of the new era, and create excellent image culture products with native characteristics. 
The author holds that, firstly, we shall introduce highlevel talents into the image serve industry in combination of Henan's image service enterprise and relevant colleges and universities, creating a good environment for them and giving full play of their talents. Secondly, we shall train and educate existing talents in combination of relevant colleges, universities and enterprises, allowing them to develop quickly and become the backbone of Henan's image industry. Thirdly, we shall unite relevant colleges, universities and enterprises, make targeted reserves for the talents and get ready for sustainable development within Henan's image industry.

\section{HENAN'S COLLEGES AND UNIVERSITIES CARRY THE Vital TASK OF TRAINING NeW PhOTOGRAPHY TALENTS}

Henan's colleges and universities carry the vital task of training Zhengzhou's image service industry talents. For a period of time, in the education and teaching process of image creation, we largely emphasize the training of technique. In cognition, some believe that they can photograph as long as they know how to use a camera. Some schools even attribute photography to the Department of Journalism, only focusing on documentary style photography. In this way, the ideological content, artistry and humanity of photography works are neglected or weakened, and its application scope is narrowed down. However, if lacking the education of these consciousnesses of humanity, the students will gradually feel powerless after taking a job in the field. Strengthening the education of humanistic quality in our education and teaching has much more far-reaching significance for students and society.

Moreover, the photography major in colleges and universities shall have wide, deep and long-term cooperation with photography enterprises. The setting of course shall mainly integrate with the photography market. The development of teaching material shall keep pace with the times. The allocation of teachers shall be scientific and reasonable. These teachers shall master the cutting-edge development conditions of the photography industry at any time. In general, the education of photography talents by Henan colleges and universities shall keep pace with the times, reframe mode and respect the needs of market development.

\section{The specific measures are as follows:}

Firstly, to transform educational concepts, breakthrough the mindset on educating new talents, give great impetus to educational reform, and implement the "studio system" of professional education. Currently, the situation of photography education and training industry as well as the performance of people in the whole photography industry are polarized. On the one hand, the skilled talents trained by skill training schools can carry a Digital Single Lens Reflex (DSLR) and take a professional job only after one to two years of training. The threshold is very low, with no requirements for educational backgrounds or quality of students' work. On the other hand, the professionally trained students educated by universities and colleges have high artistic culture but weak practicality, and have grandiose aims but puny abilities.

Secondly, whilst strengthening the students' qualityoriented education and culture base education, we shall link photography teaching with commercial operations, reforming and innovating conventional educational concepts. Meanwhile, the project teaching and commercial photography working system leads the student to go to society and serve the society, improve the students' ability of communication, shooting thought and service spirit, educate the students' comprehensive abilities of finding opportunity, cognizing society and creating life, educate and improve the students' operational ability, innovation ability and learning style, finally reaching the requirement of improving the students' practical ability to adapt to industry development. The students shall practice and prepare for future employment. Based on Zhengzhou, with the learning content closing to public life, can we better propagandize and serve this city?

\section{IMPROVEMENT OF THE IMAGE SERVICE INDUSTRY REQUIRES HIGHER INDUSTRIAL STANDARD}

Improving the core market competencies of the image service industry will be the decisive factor for the success or failure of an enterprise. The enterprise shall combine with local culture and practical situations, and establish unique artistic styles so as to be different from competitors. In addition, industry groups shall be implemented. It is suggested to mobilize the enthusiasm of various aspects to invest into the image industry. Keeping a foothold on provincial situations, highlight the features and walk on the development road of large-scales, groups, colleges and universities-oriented through the promotion of policy and the guidance of financial fund. Through the forms such as combination, merger and recombination, we shall optimize good brands and funds, create an internationally competitive large-scale image service picture market, improve the extensive growth condition of scattered, small and weak brands, rapidly develop a scale and brand economy, and the know-how, developing and driving forward the brand. Through the driving, demonstration and radiation of leading enterprises, we shall strengthen the communion and cooperation between enterprises as well as the join of upstream and downstream industries, form advantage complementation and industrial interaction to try and construct an image service industry chain. Thus driving the scale of development forward and providing enough power for improving core market competences of image product in Henan Province.

The improvement of the image service industry not only relies on core competences, but also relies on the improvement of industrial standards. I have seen the same customer photo in sample albums of three different photographic studios, and all of who claim that the photo is shot in their studio. These photos were also found on various websites. How can all of these separate companies shoot the same sample photos? When consumers select a photographic studio for wedding photos, checking the sample album and sample photos are the main bases for 
judging the photographer's shooting level. The recently introduced industrial standard--"Service Specifications of Image Industry" specifies the source of "sample album and sample photo", requires that the sample album and sample photos shall truly and effectively reflect the studios expressive ability and technological level in photography. In addition, both wedding dresses and formal dresses in pictures are white and beautiful, but in fact, most of them are dirty in the photographic studio. It is uncomfortable to wear them. The phenomenon of "wearing without washing" is very common in photographic studio. If a wedding dress is not timely cleaned and disinfected after being repeatedly used by many people, it will become the "culture medium" of microorganism. It may infect diseases, and especially cause skin diseases such as scabies. The new rule--"Service Specifications of Image Industry" has included the provision on wedding dress cleanness. The consumers can complain accordingly in case of relevant problems.

The industrial standard of "Service Specifications of Image Industry" refines main content of photography service into stages such as store reception, modeling, shooting, checking samples, post production, photo pickup, analysis and improvement of customer opinion, sample photos, sample album and sample product, and put forward corresponding specification requirement. The implementation of new standard will facilitate the standard operation of photography service organization, and better safeguard legal rights and interests of consumer. But how to strengthen industry management with this standard still needs further attention.

\section{BLENDING OF IMAGE SERVICE INDUSTRY AND Central Plain Culture}

I always believe that domestic photography has obvious trace of western culture influence, but strongly retain the ethnic characteristics of its own culture. China is a country having multiple nationalities, among which, the Han nationality has the largest population, and its root is exactly in Central China. Central China is the cradle of Yellow River civilization, having a long history. As a place located in Central Plains, Zhengzhou City has numerous cultural characteristics with local features. How to fuse local elements in the development of local culture industry is an important issue.

The cultural resources of Central Plains shall be deeply developed and accumulated to lay a solid foundation for the development of Henan's image service industry. Since Henan - which is located in Central Plains - is the main birthplace of Chinese civilization, Henan enjoys exceptional advantages in the developing image service industry. Zhengzhou's image service industry shall fully exploit the advantages in geography \& tourism resources, and turn the historical culture resources into productivity. "We shall explore and invite public bidding for these resources, and find the best photography operations company to develop these resources", said Guo Zhaoyuan, Chairman of Henan Zhengzhou Zhaoyuan Photo Group. As an enterprise, they also notice the insufficient development of local geographical resources. He feels that relevant departments of government shall sort out the geographical environment of Henan, make them into directory, invite public bidding for local photography enterprise industry, and select the strongest enterprise with the best originality to making these geographical resources or elements into products. The planned development of local themes of Henan in this way is better than the scattered development of each enterprise. The author believes that this is also the inheritance and promotion of Henan local culture.

\section{THE GOVERNMENT SHALL IMPROVE THE EFFICIENCY OF CAPITAL INVESTMENT UNDER THE GUIDANCE OF POLICY}

Firstly, leadership, organization and coordination body shall be established. The provincial Party committee and the provincial government are suggested to establish Henan's leading group on the image industry development, expected to facilitate the industry's development, with the leadership of municipal Party committee and municipal government as the front-runner. The main work is to make policy, carry out investigation and macro-control, lead and organize the healthy and ordered development of image enterprise and image organization of Zhengzhou City. Meanwhile, a joint conference system at the level of departments shall be established through referring to the practice of central government.

Secondly, a municipal level special fund for image industry development shall be set up. According to the requirement in the document of Department of Culture, it is suggested to establish Henan with provincial special funds for protecting and developing image industry, encourage excellent curators who drive the image industry to start image industry projects through measures such as encouragement, giving priority to support and soft loans, supporting distinctive and influential professional image galleries and amply rewarding the image enterprises with a mature operation. This essentially gives them a sense of professional honor and care from the government, making them transmit "positive energy" into industry development, and a want to protect the virtuous circle of image industry.

Thirdly, a photography festival with a high standard and connotation shall be regularly conducted under the leading of government. Taking the "Pingyao International Photography Festival" as an example, it has been held by Shanxi provincial government for 13 years. It has cultivated countless new photography talents for the Chinese photography field. It is a grown-up baptism for photography freshman. It provides a platform for Chinese photography to go into the world and provides a chance for world photography to inflow into China, truly living up to "Gear China to modernization, the world and the future" put forward by Deng Xiaoping.

\section{CONCLUSION}

In recent years, Henan shall center on the strategic target of constructing both a strong economic and cultural province, giving great impetus to the development of Henan's image service industry. Creating a good environment for image development there stands a chance 
of making this the most competitive industry in Henan culture today. Medium and small image enterprises and studios are continually emerged in various regions of Henan. Image majors are successively set up in some universities and colleges. The image enterprises with brand effect are under industrialization. The structure of the integration of industry-university-research-supply-marketing is gradually formed. The overall strength and influence are constantly enhanced. Henan's image service industry has obtained unprecedented development. The image service industry continuously maintained good development trends in 2014. Its facilitation to the construction of strong cultural province is increasingly obvious.

\section{REFERENCES}

[1] Wang Chuandong. Value Exceeding Image[M]. Shanghai Translation Publishing House, Shandong Fine Arts Publishing House. ISBN: 9787-5330-2345-4

[2] Liu Chang. Study on Photography and Dissemination Media[D]. Nanjing Normal University

[3] Feng Feng, Liu Qingyuan, Cai Yan, Yang Min, Yin Yangping. Image: Narration and Representation. Lingnan Art Publishing House. ISBN: 978-5362-3147-4. November, 2008 edition

[4] [U.S.] Written by Mary Warner Marien, translated by Hao Hongwei and $\mathrm{Ni}$ Yang. Photography and its Critics. ShanDong Pictorial Publishing House. ISBN: 7-80713-165-9. October 2005 edition.

[5] Zeng Yaonong. Art \& Communication[M]. Tsinghua University Press. ISBN: 978-7-302-14867-2. First edition in May 2007

[6] Guo Qingguang. Journalism \& Communication[M]. China Renmin University Press. ISBN: 7-300-03288-5/G'629. 13th edition in January 2007.

[7] Teng Shouyao. Art and Visual Perception[M]. Sichuan People's Publishing House. ISBN: 7-220-03958-1/B•159

[8] Teng Shouyao. Visual Thinking - Aesthetic Intuition Psychology[M]. Sichuan People's Publishing House.ISBN: 7-220-03958-1/B•159

[9] Qiu Zhijie, Wu Meichun. Image and Post-modern [M]. Hunan Fine Arts Publishing House. ISBN: 7-5356-1674-2. First edition in January 2002

[10] Contemporary Art[J], 2008(9). 